\title{
Patients' satisfaction with and views about treatment with disease-modifying drugs in multiple sclerosis
}

\author{
Satisfação e pontos de vista dos pacientes com esclerose múltipla em tratamento com \\ drogas modificadoras da doença \\ Caroline Vieira Spessotto 1,2, Hanaie Cavalli³, Audred Cristina Biondo Eboni4, Rafael Berlezi Machado5, \\ Analara Munardi Mousquer ${ }^{6}$, Lara Both Palazzo ${ }^{5}$, Alessandro Finkelsztejn ${ }^{5}$, Marcus Vinicius Magno \\ Goncalves ${ }^{4}$, Henry Koiti Sato ${ }^{3}$, Fabio Siquineli', Yara Dadalti Fragoso ${ }^{1}$
}

\begin{abstract}
Objective: The treatment of multiple sclerosis (MS) with disease-modifying-drugs (DMDs) is evolving and new drugs are reaching the market. Efficacy and safety aspects of the drugs are crucial, but the patients' satisfaction with the treatment must be taken into consideration. Methods: Individual interview with patients with MS regarding their satisfaction and points of view on the treatment with DMDs. Results: One hundred and twenty eight patients attending specialized MS Units in five different cities were interviewed. Over $80 \%$ of patients were very satisfied with the drugs in use regarding convenience and perceived benefits. The only aspect scoring lesser values was tolerability. Conclusion: Parameters for improving treatment in MS must include efficacy, safety, and patient satisfaction with the given DMD.
\end{abstract}

Keywords: multiple sclerosis; glatiramer acetate; interferon-beta; natalizumab; fingolimod hydrochloride.

\section{RESUMO}

Objetivo: 0 tratamento da esclerose múltipla (EM) com drogas-modificadoras-da-doença (DMDs) está evoluindo e novas drogas estão sendo comercializadas. Eficácia e segurança são aspectos cruciais nas medicações, porém a satisfação do paciente com o tratamento deve ser levada em consideração. Métodos: Entrevista individual com pacientes com EM investigando a satisfação e ponto de vista desta população em relação ao tratamento com DMDs. Resultados: Cento e vinte e oito pacientes atendidos em unidades especializadas de EM de cinco cidades diferentes foram entrevistados. Mais de $80 \%$ dos pacientes estava bastante satisfeito com as medicações utilizadas, considerando aspectos de conveniência de uso e benefício das drogas. 0 único aspecto que pontuou menos foi tolerabilidade. Conclusão: Parâmetros para melhor tratamento de EM devem incluir eficácia, segurança e satisfação dos pacientes com a DMD prescrita.

Palavras-chave: esclerose múltipla; acetato de glatiramer; interferon beta; natalizumab; cloridrato de fingolimode.

One important aspect of all treatments is the patients' satisfaction with them. Patients may not tell their doctors that they are not satisfied with a certain treatment, and this creates space for non-adherence and switching between doctors or between drugs. Such situations also give rise to expectations in relation to non-evidence based treatments. In diseases like multiple sclerosis (MS), in which the treatment is longterm and outcomes are more qualitative than quantitative, it is particularly important to know how patients feel about the disease-modifying drugs (DMDs) that are prescribed to them. Satisfaction is a complex matter to describe, since it involves fulfillment of expectations, convenience of use and measurable positive results.

DMDs for treating MS are increasing in number and complexity. Safety is an extremely important aspect of DMDs that needs to be taken into consideration, even if the drug

'Universidade Metropolitana de Santos, Departamento de Neurologia, Santos SP, Brasil;

${ }^{2}$ Residência em Clínica Médica da Angiocorpore, Santos SP, Brasil;

${ }^{3}$ Instituto de Neurologia de Curitiba, Curitiba PR, Brasil;

${ }^{4}$ Centro Hospitalar Unimed, Joinville SC, Brasil;

${ }^{5}$ Hospital de Clinicas de Porto Alegre, Porto Alegre RS, Brasil;

${ }^{6}$ Universidade Regional de Blumenau, Blumenau SC, Brasil.

Correspondence: Yara Dadalti Fragoso; Departamento de Neurologia, da Faculdade de Medicina da UNIMES; Rua da Constituição 374; 11015 -470 Santos SP, Brasil; E-mail:yara@bsnet.com.br

Conflict of interest: There is no conflict of interest to declare.

Received 12 January 2016; Received in final form 26 May 2016; Accepted 08 June 2016 
involved is not the most convenient one with regard to its mode of administration. On the other hand, sometimes efficacy comes first and safety is put at risk in order to stop high disease activity. Adverse events tend to be a deterrent to adherence and patients need to have correct expectations in this regard. Other features of MS, like fatigue, cognitive dysfunction and mood disorders ${ }^{1}$, may all contribute towards dissatisfaction and non-adherence to DMDs. The demands of patients' social and professional lives, pronouncements through internet pages and blogs, television, radio and magazines and the demands of patients' friends and relatives all create a need for better treatments for MS. Better, however, does not necessarily mean safer or more efficacious, or easier to administer or to follow up. Despite the clearly established benefits of DMDs, the rate of adherence remains moderate, at best, in the few studies assessing these parameters ${ }^{2,3,4,5}$.

The present study assessed the degree of satisfaction of patients with MS regarding treatments with DMDs prescribed for them at five different Brazilian MS Units.

\section{METHODS}

This study was approved by the Ethics Committee of Universidade Metropolitana de Santos, Brazil, in May 2015, under the registration number CAAE 46029615.6.0000.5509. Additional approval was obtained from other participating institutions, whenever required.

Patients from five different cities in the south of Brazil were invited to answer a questionnaire regarding their MS treatment (Santos, Joinville, Blumenau, Curitiba and Porto Alegre; latitudes 23S to 30S). Participation was voluntary: all the patients were invited while waiting for consultations with their neurologist. In all cities, experienced medical residents who had been specially trained for this questionnaire were responsible for the individual interviews.

Patients were included if they had been undergoing treatment with DMDs for at least one month. The questionnaire, which was specially created for this study, contained 25 items, and answers were scored from 1 to 5 on a Likert scale: 1) I do not agree at all; 2) I tend to disagree; 3) I have no opinion, 4) I tend to agree, 5) I totally agree.

The questions related to personal impressions of treatment benefits, tolerability, convenience of use and general satisfaction with the treatment. The benefit of the drug was assessed in terms of the general perception of whether the drug had the effect that it was supposed to have (for example, control of relapses). The convenience of the drug was assessed in terms of its ease of storage and use, and also whether it could be transported if necessary ( for example, for use during trips). The tolerability of the drug was evaluated in terms of its adverse events and interference with social and professional life, and whether side effects from that particular DMD were acceptable as part of the treatment. The general satisfaction with the treatment was evaluated in terms of the positive and negative aspects of quality of life since treatment with that particular DMD had started.

The scores obtained on the Likert scale for each of the questions (positive, negative or neutral) were summed and the result was used in the analyses. There was a final question in which the patients were invited to make any comments that they considered relevant. The responses to this question were not considered in the score.

The results are presented in a purely descriptive manner.

\section{RESULTS}

The cities of origin of the patients entering this study were Santos $(n=36)$, Joinville $(n=19)$, Blumenau $(n=24)$, Curitiba $(n=23)$ and Porto Alegre $(n=26)$. One hundred and twenty eight patients were interviewed individually (83 women and 45 men; median age 40 years). The median duration of treatment was 39 months, and for $50 \%$ of the patients, their initial DMD was changed at least once to another DMD. There was no specific switching pattern, although natalizumab and fingolimod were mainly used as the second or third therapeutic option. Table 1 summarizes the results on each individual statement originally scored 1 to 5 on a Likert scale. Regarding the open question, the majority of patients replied that they would like to have more efficient drugs to treat MS, and they also wanted to have the disease cured. Patients who switched DMDs had worse results regarding satisfaction with treatment (Table 2). Responses relating to the results from individual DMDs are discussed below.

\section{Glatiramer acetate}

Glatiramer acetate (Copaxone ${ }^{\circ}$ ) was the drug most used drug in the whole group of 128 patients (36.7\%). This drug was not changed for $63.8 \%$ of the patients who were initially prescribed it. Irrespective of previous changes of DMDs, $81.5 \%$ of all patients using glatiramer acetate considered that the drug was beneficial for their treatment, $86.8 \%$ considered it convenient, but only $52.7 \%$ considered it to have good tolerability, because of the daily injections. On the whole, $87.9 \%$ of the patients using glatiramer acetate were satisfied with this treatment.

\section{Interferon beta}

Although three different formulations of interferon beta are available in Brazil (Avonex ${ }^{\bullet}$, Rebif ${ }^{\star}$ and Betaferon ${ }^{\bullet}$ ), for the purpose of this study they were all considered as "interferon beta". At the time of this survey, irrespective of previous changes, these prescriptions accounted for $20.3 \%$ of the patients assessed in this study. Twenty-six patients (75\%) reported that they had previously used interferon beta, but that it had been withdrawn due to lack of efficacy or intolerable side effects. On the other hand, $27.4 \%$ of the patients had switched from other drugs to interferon beta. 
At the time of this survey, $83.5 \%$ of patients using interferon beta considered it to be beneficial, $84.2 \%$ considered it to be convenient, but only $56.5 \%$ considered it to be tolerable, mainly because of the frequent injections and flulike reactions. On the whole, $80.2 \%$ of the patients using interferon beta reported that they were satisfied with this treatment. There were no significant differences among the different formulations of interferon beta regarding reported satisfaction.

\section{Natalizumab}

Natalizumab (Tysabri ${ }^{\circ}$ ) was used by $5.5 \%$ of patients in this population. All patients using natalizumab had received at least one other therapy first (glatiramer acetate and/or interferon). Natalizumab was considered to be beneficial by $76.2 \%$ of the patients, convenient by $85.7 \%$ and tolerable by $62.5 \%$. From the whole group of patients using natalizumab, $85.7 \%$ of them were satisfied with this treatment.

Table 1. Results on the satisfaction with treatment for MS. The statements were given to 128 patients with MS who would score each sentence in 1 to 5 on a Likert scale: 1) I do not agree at all; 2) I tend to disagree; 3) I have no opinion, 4) I tend to agree, 5) I totally agree.

\begin{tabular}{|c|c|c|c|}
\hline Statments & $\begin{array}{c}1 / 2 \text { (disagree) } \\
(\%)\end{array}$ & $\begin{array}{c}3 \text { (neutral) } \\
(\%)\end{array}$ & $\begin{array}{c}4 / 5 \text { (agree) } \\
(\%)\end{array}$ \\
\hline I feel that my treatment gives me benefits & 4.5 & 10.8 & 84.7 \\
\hline I feel capable of administering the medication to myself & 9.8 & 6.4 & 83.8 \\
\hline I feel that my MS symptoms have improved with treatment & 13.3 & 11.5 & 75.2 \\
\hline After starting my treatment. I feel that my general health is good & 11.7 & 8.0 & 80.3 \\
\hline I feel that many of my symptoms are under control with treatment & 8.6 & 12.8 & 78.6 \\
\hline I believe the treatment is efficient & 3.9 & 8.3 & 87.8 \\
\hline My present treatment gives me more benefits than did the previous one & 13.8 & 17.8 & 68.4 \\
\hline The adverse events of this treatment negatively influence my physical performance & 47.7 & 9.2 & 43.1 \\
\hline The adverse events of this treatment negatively influence my mental performance & 63.6 & 10.2 & 26.2 \\
\hline I think this medication is easy to use & 53.7 & 8.5 & 37.8 \\
\hline This treatment does not interfere with my daily activities & 19.1 & 5.5 & 75.4 \\
\hline I follow the recommendations regarding therapy & 7.6 & 1.8 & 90.6 \\
\hline I feel embarrassed if someone sees me taking the medication & 69.7 & 8.0 & 22.3 \\
\hline I accept the limitations of this treatment & 2.3 & 8.8 & 88.9 \\
\hline I believe the medication is good for me & 3.3 & 4.3 & 92.4 \\
\hline The medication has more good aspects than bad ones & 3.7 & 4.6 & 91.7 \\
\hline My quality of life has improved & 8.1 & 15.3 & 76.6 \\
\hline The medication has a negative influence in my family life & 73.1 & 9.0 & 17.9 \\
\hline The medication has a negative influence in my social life & 63.2 & 6.9 & 29.9 \\
\hline I am in general satisfied with my treatment & 9.3 & 5.4 & 85.3 \\
\hline I would recommend people to treat their MS & 6.4 & 4.3 & 89.3 \\
\hline I believe the medication is efficient & 3.8 & 5.5 & 90.7 \\
\hline I feel motivated to continue my treatment & 5.0 & 4.1 & 90.9 \\
\hline
\end{tabular}

MS: multiple sclerosis.

Table 2. General impressions of patients with multiple sclerosis regarding the "disease-modifying drug" (DMD) used for their treatment. The first column presents the number of patients whose medication was switched at least once. All other columns report the impressions regarding the present treatment.

\begin{tabular}{|c|c|c|c|c|c|}
\hline Variable & $\begin{array}{l}\text { Total group } \\
(n=128)\end{array}$ & $\begin{array}{l}\text { Glatiramer acetate } \\
\qquad(n=47)\end{array}$ & $\begin{array}{l}\text { Interferon beta } \\
\quad(n=36)\end{array}$ & $\begin{array}{l}\text { Natalizumab } \\
\quad(n=7)\end{array}$ & $\begin{array}{l}\text { Fingolimod } \\
(n=28)\end{array}$ \\
\hline DMD switching & $n=54$ & $n=17(36.25 \%)$ & $n=27(57.4 \%)$ & $n=0$ & $n=0$ \\
\hline Positive view on the benefit of treatment - \% & 82.1 & 81.5 & 83.5 & 76.2 & 87.2 \\
\hline Positive view on the convenience of use - \% & 86.3 & 86.8 & 84.2 & 85.7 & 90.8 \\
\hline Positive view on the tolerability - \% & 59.9 & 52.7 & 56.5 & 62.5 & 74.1 \\
\hline Overall satisfaction with DMD - \% & 83.8 & 87.9 & 80.2 & 85.7 & 90 \\
\hline Satisfaction after changing from another DMD - \% & 69.0 & 66.7 & 66.7 & 71.4 & 70.4 \\
\hline
\end{tabular}




\section{Fingolimod}

Fingolimod (Gilenya ${ }^{\circ}$ ) was used by $22.7 \%$ of the patients in this study. This was the first oral therapy to become available in Brazil, and prescription of the drug is somewhat limited due to government restrictions on storage and distribution. The majority of the switches of DMD occurred in favor of fingolimod (72.7\% of the total number of switches). There were no records of switches from fingolimod to other drugs. Fingolimod was considered beneficial by $87.2 \%$ of the patients, convenient by $90.8 \%$ and tolerable by $74.1 \%$. Satisfaction with fingolimod was reported by $90 \%$ of the patients.

\section{Other treatments}

Azathioprine $\left(\operatorname{Imuran}^{\circ}\right)$, teriflunomide $\left(\right.$ Aubagio $\left.^{\circ}\right)$, noDMD and off-label vitamin D treatment were reported by very few patients and could not be included in this assessment. Fampridine (Fampyra ${ }^{\circ}$ ), which is used for improving gait, was not discussed here since it is not a DMD.

\section{DISCUSSION}

Patient preference and satisfaction is an important issue if adherence to treatment and medical recommendations is to be achieved. The therapeutic options available for MS are increasing and more than 10 drugs may soon be available for first-line, induction, escalation or rescue therapies. The doctor should not take into consideration the convenience of a treatment when efficacy is at stake, and should always consider safety to be an important matter in treatment choices. In the present study, the patients seemed to be satisfied with the injectable treatments (glatiramer acetate and interferon beta) to the point of maintaining these initial therapies in $43.8 \%$ of the cases. For all DMDs, over $80 \%$ of the patients perceived that they were beneficial. The convenience of oral drugs was higher than that of injectable medications, but the difference was less than $10 \%$. The same result was not observed in the $\mathrm{USA}^{6}$, where patients had a strong preference for oral drugs. A German study showed that patients prefer oral drugs over injectable ones if the administration of the pills was once a day?

The main point deserving attention is the remarkable lack of satisfaction with tolerance in relation to all drugs used to treat MS, which was around 40 to $50 \%$ for all treatments. A great discussion about the convenience of oral drugs over injectable ones and about higher benefits from newer drugs than from older ones continues to dominate MS marketing. However, what needs to be given more attention is, in fact, the tolerance of all of these treatments over the long term.

The limitations of the present study are the small sample of participants and their biased selection. The study was not designed for power of comparison among drugs. In fact, the choice of drugs is a matter of efficacy, safety and optimal response, which are individual. Not all patients respond in the same way to all drugs. The MS units participating in the study are all centers of excellence in Brazil and their populations of outpatients receive uniform attention and the best available therapy, provided by experts in the field. This tailor-made approach to patients may have given better general results regarding satisfaction with treatment.

\section{References}

1. Hildebrandt H, Eling P. A longitudinal study on fatigue, depression, and their relation to neurocognition in multiple sclerosis. J Clin Exp Neuropsychol. 2014;36(4):410-7. doi:10.1080/13803395.2014.903900

2. Twork S, Nippert I, Scherer P, Haas J, Pöhlau D, Kugler J. Immunomodulating drugs in multiple sclerosis: compliance, satisfaction and adverse effects evaluation in a German multiple sclerosis population. Curr Med Res Opin. 2007;23:1209-15. doi:10.1185/030079907X188125

3. Menzin J, Caon C, Nichols C, White LA, Friedman M, Pill MW. Narrative review of the literature on adherence to disease-modifying therapies among patients with multiple sclerosis. J Manag Care Pharm. 2013;19(1 Suppl A):S24-40. doi:10.18553/jmcp.2013.19.s1.S24

4. Lugaresi A, Rottoli MR, Patti F. Fostering adherence to injectable disease-modifying therapies in multiple sclerosis. Expert Rev Neurother. 2014;14(9):1029-42. doi:10.1586/14737175.2014.945523
5. Cohen BA, Coyle PK, Leist T, Oleen-Burkey MA, Schwartz M, Zwibel H. Therapy Optimization in Multiple Sclerosis: a cohort study of therapy adherence and risk of relapse. Mult Scler Relat Disord. 2015;4(1):75-82. doi:10.1016/j.msard.2014.09.214

6. Wilson LS, Loucks A, Gipson G, Zhong L, Bui C, Miller $E$ et al. Patient preferences for attributes of multiple sclerosis disease-modifying therapies: development and results of a ratings-based conjoint analysis. Int J MS Care. 2015;17(2)74-82. doi:10.7224/1537-2073.2013-053

7. Utz KS, Hoog J, Wentrup A, Berg S, Lämmer A, Jainsch $B$ et al. Patient preferences for disease-modifying drugs in multiple sclerosis therapy: a choice-based conjoint analysis. Ther Adv Neurol Disorder. 2014;7(6):263-75. doi:10.1177/1756285614555335 